\title{
Design by Analogy: Achieving More Patentable Ideas from One Creative Design
}

\author{
Li-Zhen Jia ${ }^{1,2,3}$, Chun-Long Wu ${ }^{2,3}$, Xue-Hong Zhu ${ }^{2}$ and Run-Hua Tan ${ }^{2,3^{*}}$ (D)
}

\begin{abstract}
A patent is a kind of technical document to protect intellectual property for individuals or enterprises. Patentable idea generation is a crucial step for patent application and analogy is confirmed to be an effective technique to inspire creative ideas. Analogy-based design usually starts from representation of an analogy source and is followed by the retrieval of appropriate analogs, mapping of design knowledge and adaptation of target solution. To diffuse one core idea into other new contexts and achieve more patentable ideas, this paper mainly centered on the first two stages of analogy-based design and proposed a patentable ideation framework. The analogical information of the source system, including source design problems and solution, was mined comprehensively through International Patent Classification analysis and represented in the form of function, behavior and structure. Three heuristics were suggested for searching the set of candidate target systems with a similar design problem, where the source design could be transferred. To systematize the process of source representation, analogs retrieval, idea transfer, and solution generation, an ideation model was put forward. Finally, the bladeless fan was selected as a source design to illustrate the application of this work. The design output shows that the representation and heuristics are beneficial, and this systematic ideation method can help the engineer or designer enhance creativity and discover more patentable opportunities.
\end{abstract}

Keywords: Design by analogy, Patentable idea generation, IPC analysis, Idea transfer heuristics, Bladeless fan

\section{Introduction}

A patent is a document, issued by an authorized governmental department, granting a set of exclusive rights to the inventor or assignee for a limited period. It is the concrete form of ideas, integrating technical information and legal information and describes any specific device, process, manufacture, composition of matter, etc. (patent statistics as economic indicators). As one kind of intellectual property, patentability of an idea or an invention is significant for individuals or industries to protect their research output. Especially for enterprises, reasonable patent applications are crucial for bypassing competitors' patents, building patent wall and avoiding patent infringement. In terms of social development, it is an effective way to encourage innovation and bring economic benefits.
Through the similarity analysis between these two domains, analogy is a transfer process of knowledge or situations from the source domain to the target [1]. From the viewpoint of psychology, similarity is categorized into attribute similarity, relational similarity and literal similarity [2]. When problem solving and creative idea generation are concerned in the scope of design context, similarity is described from the perspective of shared attributes, relations and functions of the systems [3, 4], specifically the shared structures, behaviors and functions based on the function-behavior-structure (FBS) linkage [5]. Analogy-based design (ABD) is an activity where analogy is applied into the design process for inspiring designers/engineers to generate ideas, overcome design fixation and solve design problems [6, 7].

In the theory of inventive problem solving (TRIZ), knowledge from other industries could be applied to generate high-level innovation [8], meaning that diffusing creative ideas into other contexts and making patent applications will be beneficial for individuals/enterprises to protect the core technology and discover more 
innovative opportunities. From this viewpoint, several literatures discussed some unstructured and descriptive strategies. Helms provided descriptive steps to generate divergent ideas inspired by biological stimuli [9]. Some existing software systems could also be used for ideation when the users just skim through them [10].

Within the scope of idea generation in mechanical engineering, this paper applied the framework of analogy-based design into patentable idea generation, aiming at proposing a structured method to help engineers and industries achieve more patents, build stronger patent walls, and protect their core technologies.

\subsection{Ideation Methods}

The patent law indicates that an authorized patent must meet three primary requirements: novelty, non-obviousness, and usefulness. Therein, novelty means that the invention is new and not known before the date of the patent application to prevent the prior art from being patented again. Non-obviousness requires that the invention must be sufficiently different from the state of the art, rather than a slight, unnecessary improvement. The term "usefulness" refers to the invention that could be manufactured or used to perform the intended purpose and produce positive impacts [11]. To improve the creativity of engineers and generate more novel, non-obvious, useful ideas, over 300 supportive techniques and methods are proved to be beneficial. Wherein, there are several typical and popular methods:

Synectics, proposed by Gordon, suggests the application of analogy in problem solving and idea generation [12];

Brainstorming, a group ideation technique, assists problem solvers with listing creative ideas through the cooperation of team members [13];

635 methods, C-Sketch and Gallery, which are structured skills based on brainstorming, repeat the same set of steps several times and generate ideas discretely $[14,15]$;

In Fishbone diagram, the designers are grouped together in a special way for identifying potential factors [16];

Design catalogs where past solutions are catalogued in the database and used to propose new ideas [17];

TRIZ and systematic inventive thinking (SIT) are creativity techniques that suggest to the users not only problem analyzing means, but also some corresponding problem-solving heuristics $[8,18]$.

Comprehensively, Shah classified those widely applied ideation methods into intuitive and logical groups based on the differences in thought process of the human mind [14].

Among these ideation methods, some tools in TRIZ have usually been applied to generate patentable ideas and for patent circumvention, such as evolution tree, trimming, and the integration with International Patent Classification (IPC) analysis [19-22]. Besides, Si and Lee [23] proposed a framework of strategies of bypassing patents based on judgments of patent infringement for new patentable idea generation.

The design output relies on the performance of designers, while the creativity techniques greatly impact the ideation of designers, meaning that it is of great importance whether the method could extend design space and decrease design fixation. As the key element in Synectics, analogy has been suggested as an effective and efficient means for proposing creative ideas in mechanical engineering, architecture design, bionics, etc. [4, 24-26]. Therefore, it may also be positively helpful to produce patentable ideas.

\subsection{Analogy-Based Design}

The essence of analogy-based design is that similar problems can be solved by similar solutions. Based on this logic, fruitful exploratory and explanatory studies have been conducted, aiming at enhancing the design performance. Dunbar explored the roles that analogy plays in forming hypotheses, designing experiments, fixing experiments, and explaining concepts [27]. Both Ward and Bearman classified the function of analogy into problem solving and illustration [24, 28], while Christensen and Shu distinguished it into three types:explanation, problem solving, and problem identification [7]. Moss focused on the research of appropriate timing for highly efficient application of analogy stimuli [29]. Moreover, multiple papers discussed the different performance of experts and novices stimulated by the same analogs, and the impact of analogical distance or modality of stimuli on design outputs [30-33]. Although no coherent conclusions can be obtained from the previous studies, they attempt to provide a helpful and reasonable guidance for when we should use analogy, who can use analogy, and which kind of analogy will be more efficient for facilitating the design process.

There are also some methods developed to answer the question "how can we use analogy?" Based on the different characteristics of source domain, the analogical stimuli can stem from heuristics, nature and artificial system. For the heuristics, the most typical one is TRIZ, which states that if two design problems have a similar contradiction, a similar substance-field model, or a similar evolution trend, they could be solved by similar inventive principles, standards, or evolution laws [34]. 
Furthermore, studies and advancements have been produced for searching available analogy sources from natural and artificial world [33, 35, 36].

From the viewpoint of cognitive science, many psychologists studied the information constituents and mechanism of reasoning by analogy. In artificial intelligence also, the pattern of problem solving by analogy was explored. Based on the former research, analogy-based design involves a source domain providing prior design knowledge, and a target domain, where the target problem would be solved by the inspiration of analogs, as shown in Figure 1. It mainly includes the representation of problems, the retrieval of similar problems and the adaptation of candidate solutions [33].

To extend the patent applications of one idea/invention/solution in different technical systems, this paper will start from a creative source design, followed by the retrieval of candidate target problems through similarity analysis, and then map and adjust the source solution into the target. In Section 4, a method to extract and represent analogical information of existing design is developed. In Section 7, we will discuss some heuristics used to transfer source designs into alternative target systems and propose an idea generation model based on the former study. Finally, the ideation inspired by the "bladeless fan" is applied into illustrating the research achievement further (Additional file 1).

\section{Extraction of Analogical Information of Source Design Based on IPC}

According to Gero's FBS Theory, design is represented as the mapping between function, behavior, and structure. Function is the design intentions or purposes, describing the relation between the goal of a human user and the behavior of a system. Behavior is attributed to how the structure of an artifact achieves its functions. Structure refers to the components that make up an artifact and their relationships. In the situated analogy activity, the analogical information of familiar designs is represented by structure, behavior, and function [5]. Moreover, a patent database is a huge knowledge source where $80 \%$ of technical information is not available in the non-patent literature [37]. Consequently, patent analysis could be a potentially effective method to extract function, behavior, and structure information comprehensively.

\subsection{What is IPC?}

In a patent document, invention information discloses the creative technical subject and additional information identifies the constituents of a composition or mixture, or components of a process or structure, or applications of classified technical subjects. To classify relevant technical information and retrieve it easily, the International

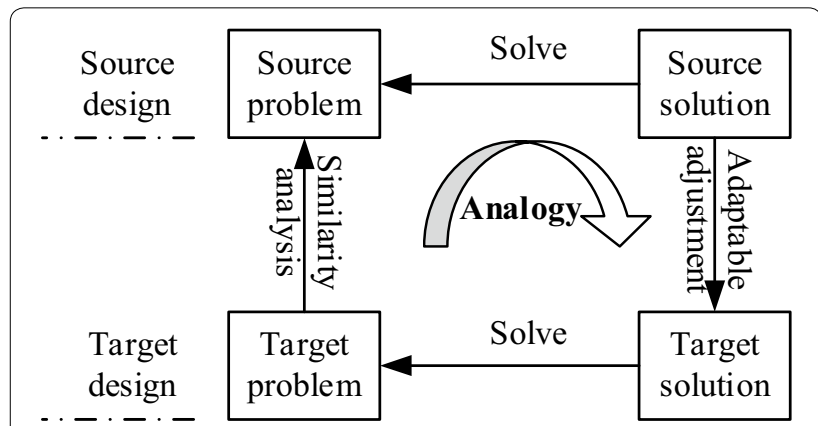

Figure 1 Process of analogy-based design

Patent Classification (IPC) is established by the Strasbourg Agreement. It provides for a hierarchical system of language independent symbols for the classification of patents and utility models according to the different areas of technology to which they pertain [38]. The contents of lower hierarchical levels are subdivisions of the contents of the higher hierarchical levels.

\subsection{Available Analogical Information Retrieval from IPC}

The lowest hierarchy of IPC, subgroup, precisely defines a field of subject matter considered to be useful for "searching" purposes. Ji et al. [39] retrieved the function, effect, and structure knowledge from the titles of IPC. In this paper, we reclassified them into function, behavior, and structure. According to the objective description of the titles of IPC, the function information only reflects what the design works for from the perspective of the technical system and not the environment or person. Behavior describes the working process of the technical system and shows how the function is delivered. It is composed of working and/or phenomenon. Wherein, principle is a rule or law concerning a natural phenomenon, such as the principle of the conservation of mass or the right-hand rule for inductive fields; phenomenon means any state or process known through the senses rather than by intuition or reasoning. Even though the main function of two systems is different, they can still work in a similar way if they have similar sub-functions. As such, behavior information could also be a start point to search for alternative problems. Structure information is represented from two points of view. In one case, it contains the "subsystem - system - supersystem" hierarchical level, reflecting the device, product, or industry to which the components/device belongs. The other case includes the key characteristics and relationships of parts related to the corresponding behavior and function.

In the following, the titles of subgroups in section $\mathrm{F}$ (mechanical engineering, lighting, heating, and 
weapons) would be taken as examples to explain the former information.

1) Function information:

F15B11/04: for controlling the speed.

F04B53/08: cooling (of machines or engines in general F01P); heating; preventing freezing.

It is usually described by only an operational verb, operational verb + noun, or their combinations.

2) Behavior information:

F21L 13/08: by reciprocating pusher actuated by hand.

F21V14/02: by movement of light sources.

F25B9/04: using vortex effect.

F42B22/04: influenced mines, e.g., by magnetic or acoustic effect.

The former two subgroups deliver the working phenomenon, while the latter two reveal the working effect.

3) Structure information:

F03D1/06: rotors.

F04C19/00: rotary-piston pumps with fluid ring or the like, specially adapted for elastic fluids.

F21L13/00: electric lighting devices with built-in electric generators (with solar cells F21L4/00).

Structure knowledge is often described by components / devices with or without characteristics /constraints.

\section{Alternative Problem Identification and Building Ideation Model}

In design by analogy, it's a challenge to retrieve appropriate analogs, meaning that it is also difficult to find the alternative contexts where the source design could be transferred. In this section, we proposed three heuristics based on the representation of analogical information and integrated the above-mentioned research into an ideation framework.

\subsection{Heuristics to Transfer Design into Other Contexts}

To guide designers to find the target contexts and speed up the idea transfer process, which are closely related to the representation of the source, this part will provide three abstract heuristics and examples to describe the searching process.

Heuristic 1: The search roadmap driven by function information. The alternative problems could be searched and solved or partially solved by the source design, since they have the same or similar functions.

For example, taking the idea of cleaning an electronic component with ultrasonic as analogy source.
The analysis of source system:

Ultrasonic cleaning is an efficient way to remove dirt and can be used to clean many complex structures in the electronics field.

The analysis of analogy characteristic:

The function "clean/separate dirt" is taken as the analogical stimuli to retrieve the candidate new contexts.

The transfer and mapping from source design to target: The idea of using ultrasonic for cleaning could be also applied into the improvement of washing machine, the design of dishwasher, toothbrush, etc.

Heuristic 2: The search roadmap by behavior information. The same or similar behavior could inspire engineers to search the alternative problems. Here, we highlight the "working phenomenon and process" part, which could be explained by the logic of evolution laws in TRIZ.

For example, taking the automatic washing machine as the analogy source.

The analysis of source system:

The design of automatic washing machine delivers its function controllably, which reduces human involvement.

The analysis of analogy characteristic:

Its development is in accordance with the evolution trend "human $\rightarrow$ human + tool $\rightarrow$ human + powered tool $\rightarrow$ human + semi-automated tool $\rightarrow$ human + automated tool $\rightarrow$ automated tool" [40].

The transfer and mapping from source design to target: The "reducing human involvement" working process of washing machine could be also applied into the design of coffee machines, soybean milk machines, camera, and even self-learning software systems.

Heuristic 3: The search roadmap driven by structure information. Based on the similar subsystem/supersystem, with which the source and target interact, the alternative problems could be discovered.

For example, taking the inverter air conditioner as analogy source.

The analysis of source system:

The idea of applying variable-frequency drive into air conditioner could solve the high energy consumption and high noise problems.

The analysis of analogy characteristic:

As the variable-frequency drive interacts with compressor, we can take the compressor as the structure information to search the target system which it is related to. 
The transfer and map from source design to target: The idea of using inverter compressor could be also applied into the design of refrigerator.

\subsection{Process Model for Patentable Idea Generation}

The heuristics provide some suggestions to engineers for discovering new problems and transferring creative design into other situations so that they can achieve more patentable ideas. To systematize the process of source representation, analogs retrieval, idea transfer, and solution generation, a five-step ideation model was put forward based on the thinking process of analogical reasoning, as shown in Figure 2.

Step 1: Select the analogy source.

The analog can be a new idea developed by the engineers themselves or an idea acquired by chance from other industries.

Step 2: Representation of the analogy source.

Encoding the source design with similar information provides a scaffold for the similarity analysis between the source and target. As discussed in Section 6, since the titles of IPC implies the required representation, we can achieve all the information related to the source design through IPC analysis and group them into function, behavior and structure information. In this stage, some patent analysis software or website is required to reduce the difficulty of dealing with IPC information when the number of patents retrieved is large. The users could mainly focus on the relevant IPC categories with the aid of some distribution graphs delivered by the tool. In this paper, a website, https://analytics.patsnap.com/patents, was selected for the case.

Step 3: $\quad$ Search of the alternative problems.

The heuristics are used to provide some guidelines to the engineers for selecting and determining the target candidates. The target systems may deliver the similar function, perform the similar behavior or be characterized by the similar structure with the source design.

Step 4: Transfer of the ideas.

In this step, engineers will map the source design into the target candidates and make appropriate adjustment to adapt the new contexts and constraints. If the ideas can be transferred successfully, continue going to Step 5; if not, go back to Step 3.

Step 5: Set of new patentable ideas.

According to the primary requirements (novelty, non-obviousness, and usefulness) of patent laws, whether the idea could be patentable will be checked for avoiding patent infringement. If there exists the infringement risk, the engineers can try some suggested strategies to bypass the relevant patents.

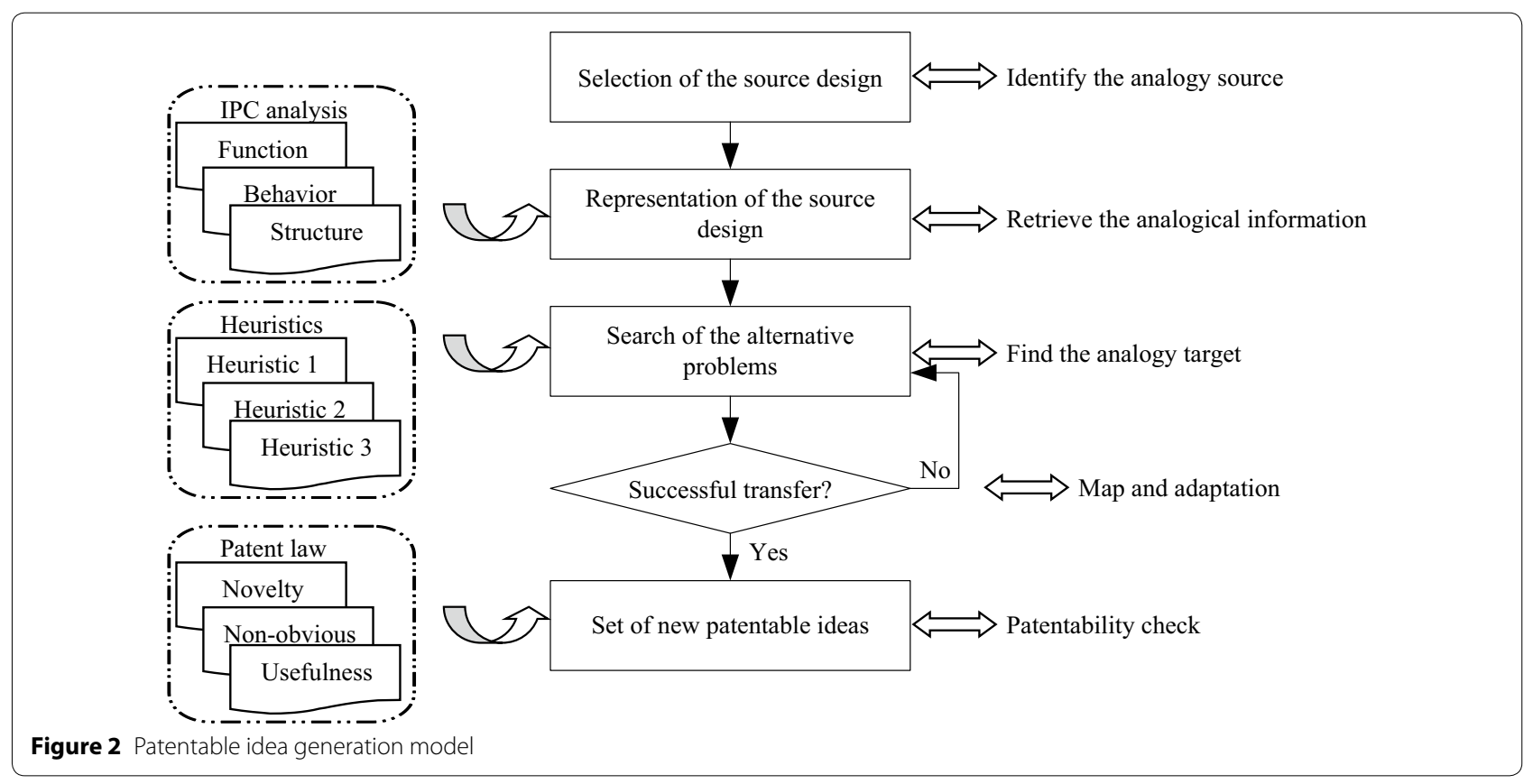




\section{Case Study}

In this section, we selected the "bladeless fan" as the source design to illustrate the above research. The bladeless fan was first manufactured by the Dyson Company and was named the Air Multiplier. As shown in Figures 3, 4 , the working principle is that the air is drawn in by a fan in the base, directed up into a ring, and comes out from the crack, without external blades.

\subsection{Representation of the Source Design}

As the case study was performed in China, only the Chinese patent database was selected. We chose "bladeless fan," "air multiplier" and "Coanda" as key words and typed the Boolean operation "bladeless fan or air multiplier or Coanda" in the "Title/Abstract/Claims" item, then searched the patents and analyzed IPC through the website https://analytics.patsnap.com/patents, as shown in Figures 5, 6.

Overall, there are more than 100 IPC subgroups. Among them, around 10 subgroups concern the function information, eight subgroups describe the relevant behavior information, 12 subgroups are about the structure and the others are not relevant to our topic. Some subgroups are the integrated description of function, behavior, and structure. For instance:

1) Main function information

F04F5/16: displacing elastic fluids.

F04D25/08: the working fluid being air, e.g. for ventilation.

A61L9/00: disinfection, sterilization, or deodorization of air.

F24C15/20: removing cooking fumes.

$\mathrm{B} 60 \mathrm{H} 1 / 00$ : heating, cooling, or ventilating devices.

...

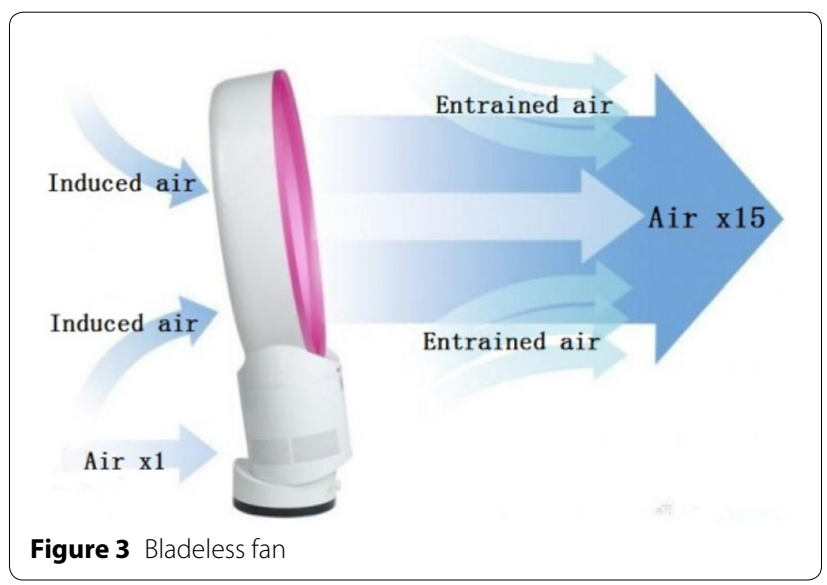

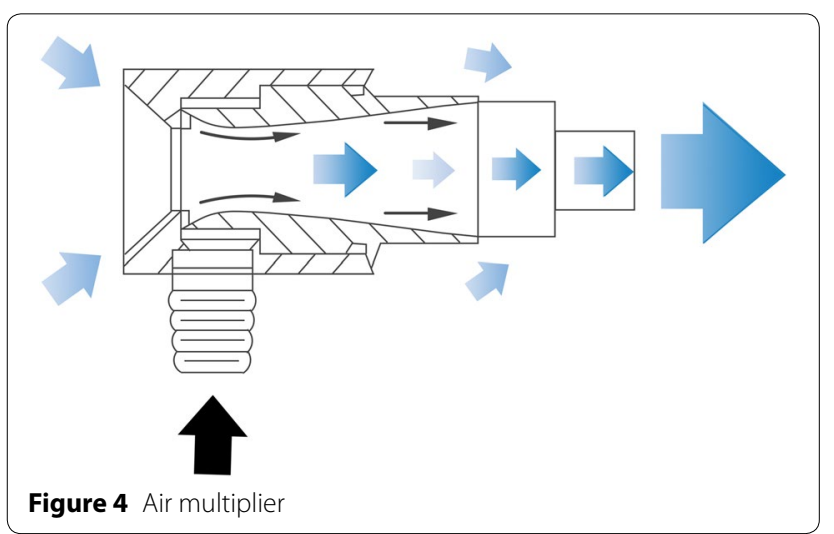

2) Main behavior information B07B7/00: selective separation of solid materials carried by, or dispersed in, gas currents.

F24H3/02: with forced circulation.

F24H3/04: the air being in direct contact with the heating medium, e.g., electric heating element.

B08B5/00: cleaning by methods involving the use of air flow or gas flow.

F24F6/12: by forming water dispersions in the air. ...

3) Main structure information

F04D25/00: pumping installations or systems specially adapted for elastic fluids.

F04F5/00: jet pumps, i.e., devices in which fluid flow is induced by pressure drop caused by velocity of another fluid flow.

F04B41/00: pumping installations or systems specially adapted for elastic fluids.

F04D29/54: fluid-guiding means, e.g., diffusers, B60H1/34: nozzles; air-diffusers.

4) The combination of function-behavior-structure information

A47L5/14: cleaning by blowing-off, also combined with suction cleaning.

B65H51/16: devices for entraining material by flow of liquids or gases, e.g., air-blast devices (blowing slag wool in molten state C03B 37/06).

After the analysis of all the relevant IPC and patents, the analogical information is shown in Figure 7.

\subsection{Patentable Idea Generation}

In this part, some examples generated by the master students from the school of mechanical engineering in our research team will be shown, to whom the working principle of the source design, the representation of function, behavior, and structure and the heuristics have been explained comprehensively before ideation. 


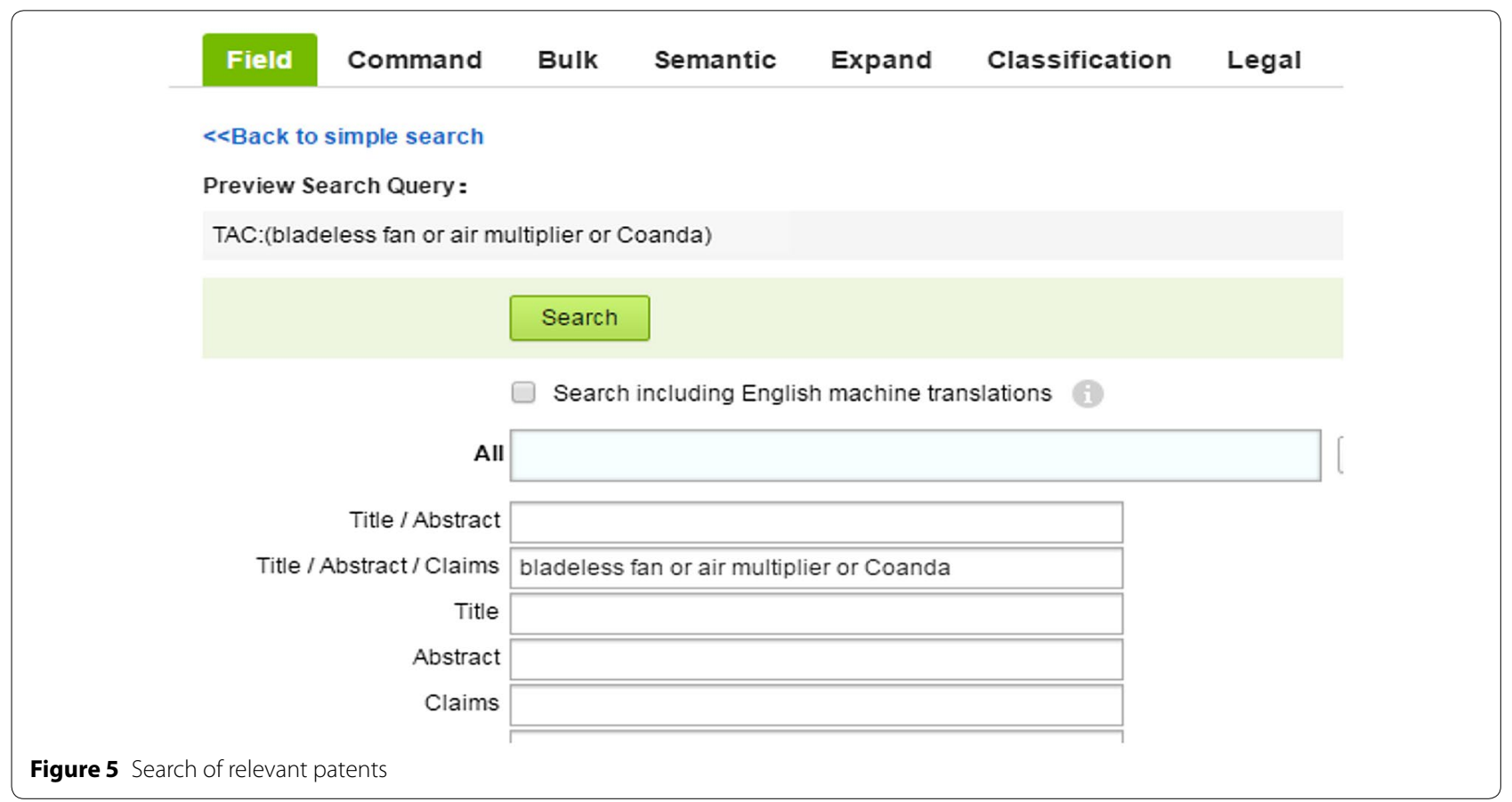

\begin{tabular}{|c|c|c|c|c|}
\hline \multicolumn{5}{|c|}{ Top IPC } \\
\hline & \multirow[t]{2}{*}{$\begin{array}{l}\text { F04F5/16.. displacing elastic } \\
\text { fluides }[1,2006.01]\end{array}$} & \multirow[t]{2}{*}{$\begin{array}{l}\text { F04F5/44.. Component } \\
\text { parts, details, or accessories } \\
\text { not provided for in, or of } \\
\text { interest apart from, groups } \\
\text { F04F5/02-F04F5/42 } \\
{[1,2006.01]}\end{array}$} & $\begin{array}{l}\text { F04B } 41 / 06 . . \\
\text { Combinations of two } \\
\text { or more pumps }[1,2006.01]\end{array}$ & $\begin{array}{l}\text { F24F11/02.. } \\
\text { Arrangement or } \\
\text { mounting of control } \\
\text { or safety devices } \\
{[1,2006.01]}\end{array}$ \\
\hline & & & $\begin{array}{l}\text { F04D27/00.. Control, e.g. } \\
\text { regulation, of pumps, } \\
\text { pumping nstallations or } \\
\text { pumping systems specially } \\
\text { adapted for elastic fluids } \\
{[1,2006.01]}\end{array}$ & $\begin{array}{l}\text { F04D29/40.. } \\
\text { Casings; } \\
\text { Connections for } \\
\text { working fluid } \\
{[1,2006.01]}\end{array}$ \\
\hline & $\begin{array}{l}\text { F04D25/08.. the working fluid } \\
\text { being air, e.g. for } \\
\text { ventilation [1,2006.01] }\end{array}$ & $\begin{array}{l}\text { F04F5/46.. Arrangements } \\
\text { of nozzles }[1,2006.01]\end{array}$ & $\begin{array}{l}\text { F04D29/66.. Combating } \\
\text { cavitation, whirls, noise, } \\
\text { vibration, or the like } \\
\text { (gas-flow silencers for } \\
\text { machines or engines in } \\
\text { general F01N); Balancing } \\
\text { (surge control F04D 27/02) } \\
{[1,2006.01]}\end{array}$ & $\begin{array}{l}\text { F24F5/00.. } \\
\text { Air-conditioning } \\
\text { systems or } \\
\text { apparatus not } \\
\text { covered by group } \\
\text { F24F 1/00 or } \\
\text { F24F 3/00 } \\
{[1,2006.01]}\end{array}$ \\
\hline
\end{tabular}

Heuristic 1: The search roadmap driven by function information.

Taking "moving," "separating," and "moving substances" as analogical stimuli, the students mapped the idea into the modified design of a medlar picking machine, where the medlar could be separated from the tree through the movement of the surrounding air.

Specifically, the new design of picking up medlar is described in Figure 8 [41]. The air multiplier was applied, in which one of the inlets provided the compressed air, another one was used for sucking medlar, and the outlet was for blowing the surrounding leaves to avoid the blocking problem. This idea could reduce the damage of medlar and fatigue of the user caused by the existing vibratory medlar picking machine.

Heuristic 2: The search roadmap driven by behavior information. 


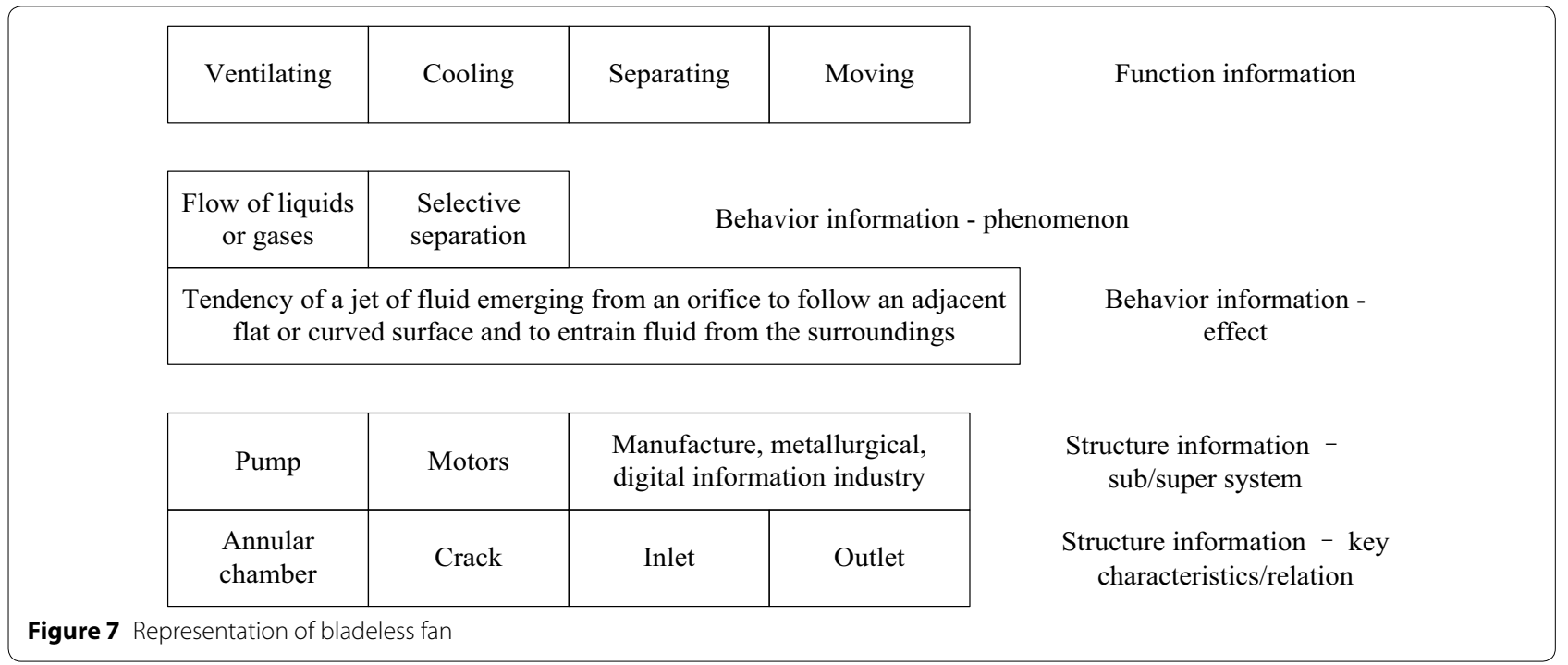
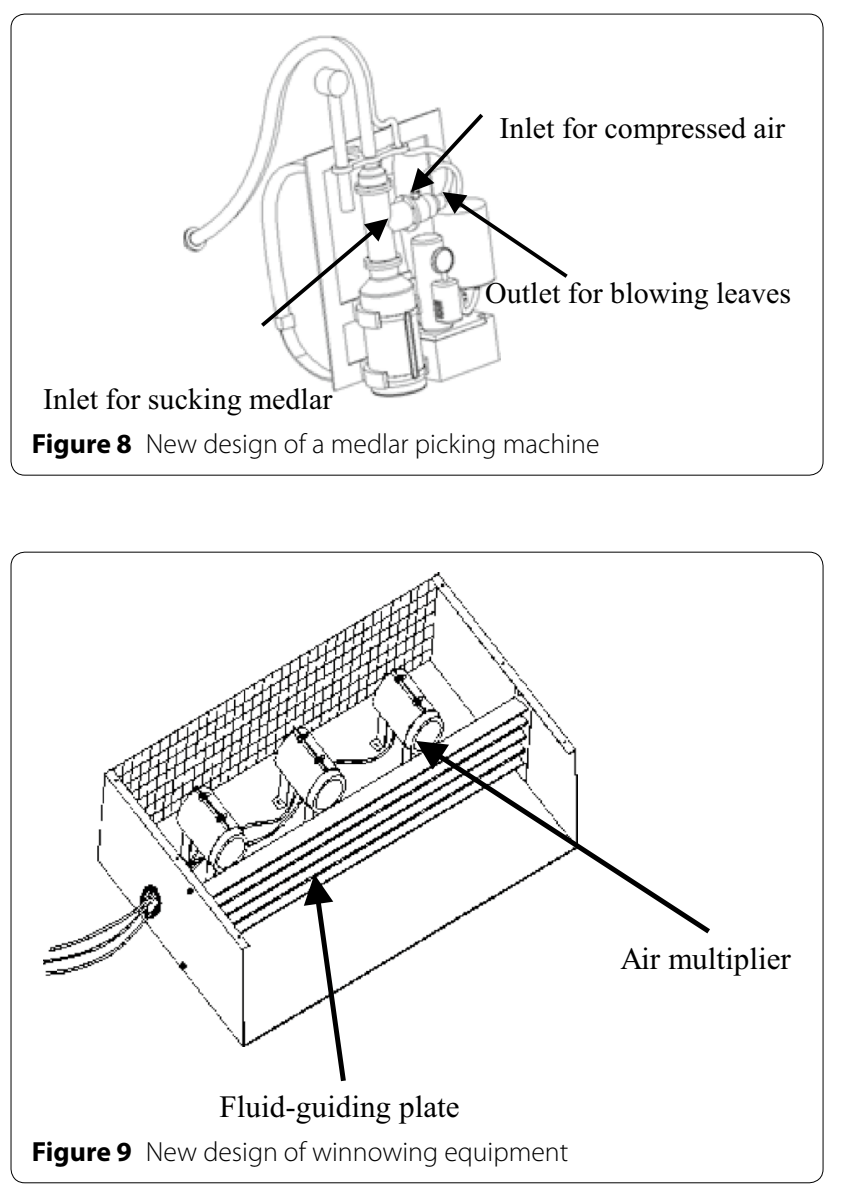

Taking the phenomenon of "selective separation" as analogical stimuli, the students finally mapped the idea into the design of the winnowing equipment in the harvester. In this context, they also used the mechanical

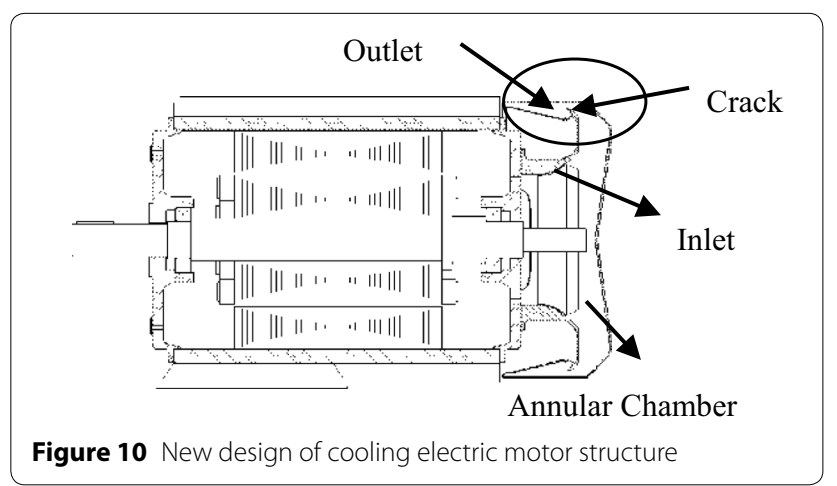

parts of the air multiplier, shown in the following Figure 9 [42]. The quantity of air multipliers could be changed according to the requirements and the fluid-guiding plate was designed for directing and separating the air flow.

Heuristic 3: The search roadmap driven by structure information.

Using one of the structure information, motors, as the alternative system, students tried to apply the source design to improve the efficiency of heat dissipation. The key structure characteristics, "annular chamber", "crack", "inlet", and "outlet" of the bladeless fan, were transferred and mapped to cool both the inside and outside of the motor. The new cooling design of electric motor was generated in Figure 10 [43].

\section{Conclusions}

This paper reviews knowledge about patents and several typical ideation methods. It has proven that analogy is a valuable technique to generate more creative ideas. 
As such, we lead the insight into analogy-based design to achieve more patent applications for protecting the core technologies and extending the range of intellectual property. Based on the research of how people solve problems by analogy in the field of psychology and artificial intelligence, the steps involve encoding the source, retrieving the analog, mapping the source solution into the target, and adapting the mapped design. This paper mainly focused on the former two stages. To represent the source design, IPC analysis was applied to uncover almost all relevant functions, behaviors, and structure information. To retrieve the alternative contexts, three abstract heuristics were put forward to transfer and map the design into the alternative target systems. To illustrate the use of the studied method more clearly, a structured patentable idea generation frame was discussed, and the bladeless fan was selected as a source design to generate more creative ideas.

The representation of analogical information is effective, and the idea generation process is beneficial to diffuse ideas into other contexts and discover innovative opportunities. However, the heuristics to retrieve target candidates are general guidelines and deserve to be explored further in future research.

\section{Additional file}

Additional file 1. Brief introduction of the paper.

\section{Authors' Contributions}

R-HT was in charge of the whole trial; L-ZJ wrote the manuscript; C-LW and $\mathrm{X}-\mathrm{HZ}$ assisted with patents analyses and data collection. All authors read and approved the final manuscript.

\section{Author details}

${ }^{1}$ Civil Aviation University of China, Tianjin 300300, China. ${ }^{2}$ Hebei University of Technology, Tianjin 300401, China. ${ }^{3}$ National Engineering Research Center for Technological Innovation Method and Tool, Tianjin 300401, China.

\section{Authors' Information}

Li-Zhen Jia, born in 1989, is currently working at Civil Aviation University of China, China. She received her PhD degree on Mechanical Engineering from Hebei University of Technology, China, in 2018. Her research interests include innovative design. Tel: +86-15602072517; E-mail: jializhen_1314@163.com.

Chun-Long Wu, born in 1986, is currently an assistant professor at National technological Innovation Method and Tool Engineering Research Center, Hebei University of Technology, China. He received his doctoral degree from Zhejiang University, China, in 2015. His research interests include function modeling, TRIZ, function and affordance based design and smart product design. Tel: +86-15822618624; E-mail: wuchunlong@hebut.edu.cn.

Xue-Hong Zhu, born in 1987, is currently a PhD candidate at Hebei University of Technology, China. He received his master degree on Mechanical Engineering from Hebei University of Technology, China, in 2013. Tel: +8613820044357; E-mail: jishezxh@163.com.

Run-Hua Tan, born in 1958, is currently a professor, a PhD candidate supervisor and vice-president at National Technological Innovation Method and Tool Engineering Research Center, Hebei University of Technology, China. His main research interests include product design, innovative design, inventive problem solving. E-mail: rhtan@hebut.edu.cn.

\section{Acknowledgements}

We would like to thank the support of the National Natural Science Foundation (Grant No. 51675159), Human Resource and Social Security Project of Hebei Province (No. JRS-2016-3097), the State Scholarship Fund from China Scholarship Council and the contribution of Professor Zhang, Dr. Sara Salimi, Lei Zhao, Yang Qiu, et al. during the research period.

\section{Competing Interests}

The authors declare no competing financial interests.

Ethics Approval and Consent to Participate

Not applicable.

\section{Publisher's Note}

Springer Nature remains neutral with regard to jurisdictional claims in published maps and institutional affiliations.

Received: 26 June 2017 Accepted: 16 April 2018

Published online: 06 May 2018

\section{References}

1. L Zhang, Z Q Xin. Review on the research in analogical reasoning. Psychological Research, 2009, 2(2): 9-15. (in Chinese)

2. $\mathrm{R} L$ Goldstone, $\mathrm{D} L$ Medin, D Gentner. Relational similarity and the nonindependence of features in similarity judgments. Cognitive Psychology, 1991, 23(2): 222-262. https://doi.org/10.1016/0010-0285(91)90010-I.

3. A K Goel. A 30-year case study and 15 principles: Implications of an artificial intelligence methodology for functional modeling. Artificial Intelligence for Engineering Design, Analysis and Manufacturing, 2013, 27(3): 203-215. https://doi.org/10.1017/s0890060413000218.

4. P A Verhaegen, J D'hondt, D Vandevenne, et al. Identifying candidates for design-by-analogy. Computers in Industry, 2011, 62(4): 446-459. https:// doi.org/10.1016/j.compind.2010.12.007.

5. B Hamraz, N H M Caldwell, TW Ridgman, et al. FBS linkage ontology and technique to support engineering change management. Research in Engineering Design, 2015, 26(1): 3-35. https://doi.org/10.1007/ s00163-014-0181-9.

6. D P Moreno, LT Blessing, M C Yang, et al. Overcoming design fixation: Design by analogy studies and nonintuitive findings. Journal of Mechanical Design, 2016, 30(2): 185-199. https://doi.org/10.1017/ s0890060416000068.

7. BT Christensen, C D Schunn. The relationship of analogical distance to analogical function and preinventive structure: The case of engineering design. Memory \& cognition, 2007, 35(1): 29-38. https://doi.org/10.3758/ bf03195939.

8. G Altshuller. Creativity as an exact science. New York: Gordon and Breach, 1984

9. M E Helms, S S Vattam, A K Goel, et al. Problem-driven and solution-based design: twin processes of biologically inspired design. Proceedings of 28th Annual Conference of the Association for Computer Aided Design in Architecture, 2008: 94-99.

10. B Sarkar, A Chakrabarti, G K Ananthasuresh. A new approach to conceptual design synthesis of sensors. Proceedings of 3rd International Conference on Design Creativity, Bangalore, India, Jan 12-14, 2015: 1-8.

11. USPTO. Novelty and Non-Obviousness, Conditions for Obtaining a Patent Alexandria: United States Patent and Trademark Office, 2011. (201610-20). [2017-03-27]. https://www.uspto.gov/patents-getting-started/ general-information-concerning-patents\#heading-4.

12. W J J Gordon. Synectics, the development of creative capacity. New York: Harper, 1961.

13. A Osborn. Applied imagination. New York: Scribners, 1979.

14. J J Shah, S V Kulkarni, N Vargas-Hernandez. Evaluation of idea generation methods for conceptual design: effectiveness metrics and design of experiments. Journal of Mechanical Design, 2000, 122(4): 377-384. https:// doi.org/10.1115/1.1315592.

15. A B VanGundy. Techniques of structured problem solving. 2nd ed. New York: Van Nostrand Reinhold, 1988. 
16. H Fogler, S Le Blanc. Strategies for creative problem solving. New York: Prentice Hall, 1995.

17. G Pahl, W Beitz. Engineering design —A systematic approach. 2nd ed. London: Springer, 1996.

18. E N Sickafus. Unified structured inventive thinking: How to invent. Grosse lle: NTELLECK, 1998.

19. $M L i, X$ Ming, $M$ Zheng, et al. A framework of product innovative design process based on TRIZ and Patent Circumvention. Journal of Engineering Design, 2013, 24(12): 830-848. https://doi.org/10.1080/09544828.2013.856 388.

20. M Li, X Ming, L He, et al., A TRIZ-based trimming method for patent design around. Computer-Aided Design, 2015, 62: 20-30. https://doi. org/10.1016/j.cad.2014.10.005.

21. P Jiang, R H Zhang, J G Sun, et al. Method and application of patent design around based on TRIZ. Computer Integrated Manufacturing Systems, 2015, 21(4): 914-923. https://doi.org/10.13196/j.cims.2015.04.006. (in Chinese)

22. P Jiang, C Wang, J G Sun, et al. Method and application of patented design around by combination of IPC cluster analysis and TRIZ. Journal of Mechanical Engineering, 2015, 51(7): 144-154. https://doi.org/10.3901/ jme.2015.07.144. (in Chinese)

23. S Chunlin, $\mathrm{K} L$ Lee. The strategy of designing around existing patents in technology innovation: case study of critical technology of OTFT. Journal of Chinese Entrepreneurship, 2010, 2(3): 270-281. https://doi. org/10.1108/17561391011078758

24. C Bearman, L J Ball, T C Ormerod. An exploration of real-world analogical problem solving in novices. Proceedings of the Annual Meeting of the Cognitive Science Society, Mahwah, America, 2002: 101-106.

25. D P Moreno. A A Hernandez, M C Yang, et al. Fundamental studies in Design-by-Analogy: A focus on domain-knowledge experts and applications to transactional design problems. Design Studies, 2014, 35(3): 232272. https://doi.org/10.1016/j.destud.2013.11.002.

26. F Rosa, G Cascini, A Baldussu. UNO-BID: unified ontology for causalfunction modeling in biologically inspired design. International Journal of Design Creativity and Innovation, 2015, 3(3-4): 177-210. https://doi.org/10. 1080/21650349.2014.941941.

27. K Dunbar. The analogical paradox: Why analogy is so easy in naturalistic settings yet so difficult in the psychological laboratory. In: D Gentner, K $J$ Holyoak, B N Kokinov. The analogical mind: Perspectives from cognitive science. Cambridge: MIT Press, 2001: 313-334 [2017-05-20].

28. TB Ward. Analogical distance and purpose in creative thought: Mental leaps versus mental hops. In: KJ Holyoak, D Gentner, B N Kokinov. Advances in analogy research: Integration of theory and data from the cognitive, computational, and neural sciences. Sofia: New Bulgarian University, 1998: 221-230.
29. ITseng, J Moss, J Cagan et al. The role of timing and analogical similarity in the stimulation of idea generation in design. Design Studies, 2008, 29(3): 203-221. https://doi.org/10.1016/j.destud.2008.01.003.

30. O Ozkan, F Dogan. Cognitive strategies of analogical reasoning in design: Differences between expert and novice designers. Design Studies, 2013, 34(2): 161-192. https://doi.org/10.1016/j.destud.2012.11.006.

31. C Chai. F Cen, W Ruan, et al. Behavioral analysis of analogical reasoning in design: Differences among designers with different expertise levels. Design Studies, 2015, 36: 3-30. https://doi.org/10.1016/j. destud.2014.07.001.

32. J Chan, S P Dow, C D Schunn. Do the best design ideas (really) come from conceptually distant sources of inspiration? Design Studies, 2015, 36: 31-58. https://doi.org/10.1016/j.destud.2014.08.001.

33. I S Linsey, A B Markman, K L Wood. Design by analogy: a study of the WordTree Method for problem re-representation. Journal of Mechanical Design, 2012, 134(4): 041009. https://doi.org/10.1115/1.4006145.

34. R H Tan. Process of two stages analogy-based design employing TRIZ. International Journal of Product Development, 2006, 4(1-2): 109-121. https://doi.org/10.1504/ijpd.2007.011537.

35. H Cheong, L H Shu. Using templates and mapping strategies to support analogical transfer in biomimetic design. Design Studies, 2013, 34(6): 706728. https://doi.org/10.1016/j.destud.2013.02.002.

36. S Vattam, B Wiltgen, M Helms, et al. DANE: Fostering Creativity in and through biologically inspired design. In: T Taura, Y Nagai, Design Creativity 2010. London: Springer-Verlag London, 2011: 115-122. https://doi. org/10.1007/978-0-85729-224-7.

37. J J Baruch, L F Parker, W S Lawson. Technology Assessment \& Forecast. Washington: Department of Commerce, 1977.

38. WIPO. International Patent Classification: Guide to the IPC. Switzerland: World Intellectual Property Organization, 2017. [2017-05-08]. http://www. wipo.int/export/sites/www/classifications/ipc/en/guide/guide_ipc.pdf.

39. Y Ji, Q Y Qiu, P E Feng, et al. Extraction and utilization of design knowledge in international patent classification. Journal of Zhejiang University (Engineer Science), 2016, 50(3): 412-418. (in Chinese)

40. D Mann. Hands-on systematic innovation. Clevedon: IFR Press, 2002.

41. H G Zhang, B H Xu, Y D Zhou, et al. Air suction type medlar picking machine: CN, CN103141220B. 2015-03-11[2017-05-22]. (in Chinese)

42. H G Zhang, WY Zhao, P Zhang, et al. Winnowing device of harvester: $C N$, CN103283415B. 2015-11-04 [2017-05-22]. (in Chinese)

43. H G Zhang, Y Qiu, H K Guo, et al. Motor heat dissipation apparatus: CN, CN104167871B. 2016-09-07 [2017-05-22]. (in Chinese)

\section{Submit your manuscript to a SpringerOpen ${ }^{\circ}$ journal and benefit from:}

- Convenient online submission

- Rigorous peer review

- Open access: articles freely available online

- High visibility within the field

- Retaining the copyright to your article

Submit your next manuscript at $\boldsymbol{\nabla}$ springeropen.com 